\title{
Hydrogeochemical Characteristics of Fluoride in the Groundwater of Shuangliao City, China
}

\author{
Ying Sun ${ }^{1,2,3}$, Xiujuan Liang ${ }^{1,2,3,}$, Changlai Xiao ${ }^{1,2,3}$, Ge Wang ${ }^{1,2,3}$, and Fanao Meng ${ }^{1,2,3}$ \\ ${ }^{1}$ Key Laboratory of Groundwater Resources and Environment, Ministry of Education, No 2519, \\ Jiefang Road, Changchun 130021, PR China \\ ${ }^{2}$ National-Local Joint Engineering Laboratory of In-situ Conversion, Drilling and Exploitation \\ Technology for Oil Shale, No 2519, Jiefang Road, Changchun 130021, PR China \\ ${ }^{3}$ College of New Energy and Environment, Jilin University, No 2519, Jiefang Road, Changchun \\ 130021, PR China
}

\begin{abstract}
This study investigated the hydrogeochemical characteristics of fluoride in the groundwater of Shuangliao City. This paper analyzes the effects of different forms of hydrochemistry and the chemical speciation of fluorine in water. The results showed that an area of high fluorine was located in the northern section of Shuangliao City, and the soil salinization degree was also high in this area. The chemical composition of groundwater was mainly formed by the evaporation-concentration process; both $\mathrm{pH}$ (weak alkaline environment) and total dissolved solids (TDS) had a positive effect on fluorine enrichment within a certain range; $\mathrm{Na}^{+}$and $\mathrm{F}^{-}$ had significant positive correlation, $\mathrm{HCO}_{3}{ }^{-}$and $\mathrm{F}^{-}$had a weak positive correlation, and $\mathrm{Ca}^{2+}$ was the only ion with a negative correlation with $\mathrm{F}^{-}$.
\end{abstract}

\section{Introduction}

Fluoride is an essential trace element in the human body that can harden tooth enamel within the optimal intake concentration range $(0.5 \sim 1.5 \mathrm{mg} / \mathrm{L})$ and can effectively reduce the incidence of dental caries. Excessive intake $(>1.5 \mathrm{mg} / \mathrm{L})$ can cause endemic fluorosis, such as dental fluorosis and skeletal fluorosis [1].

Fluorine poisoning caused by drinking water, due to abnormally high concentrations in the environment is a familiar local disease and is prevalent in the world [2]. Shuangliao City is a fluorosis hot spot in Jilin Province [3], and the disease is focused in the northern part of the city. Groundwater is the main source of water for the residents, industrial and agricultural production of Shuangliao City. Therefore, studies of the hydrogeochemical characteristics of fluorine in the groundwater under Shuangliao City are needed.

\section{Study Area}

Shuangliao City is located between the Songnen Plain and the East-West Liaohe Plain. The geology consists of continental mudstone and sandstone of Cretaceous to Quaternary age in

\footnotetext{
*Corresponding author: 1ax64@126.com
} 
the study area. The aquifer systems in this area can be divided into loose rock pore water and fragmental rock pore water. The groundwater extracted from the research area formed in three different conditions: (1) The recharge of underground water: precipitation infiltration supply, lake supply, surface water infiltration supply, and irrigation water supply; (2) Throughflow of underground water: north of Songliao watershed, the runoff of water in the upper Pleistocene layer of the study area was from northeast to southwest, which was from Songliao watershed to Songnen plain; (3) The loss of underground water: evaporation from soil, lakes, and artificial exploitation.

To study the spatial distribution of fluorine content in groundwater, a field investigation was carried out in July 2017, and the water level of 947 wells was measured and 81 wells were selected from these for groundwater quality sampling. From these data, a contour map of fluorine concentration by Kriging was made (Fig. 1). As seen in Fig. 1 (a), the $\mathrm{F}^{-}$ concentration in the northern section of the study area is the largest, and the degree of salinization of the soil is also the highest. The soil also tastes salty and grass does not grow in this location. According to the work of Sun et al. [3], high fluorine levels in groundwater are observed within the area of endemic fluorosis.
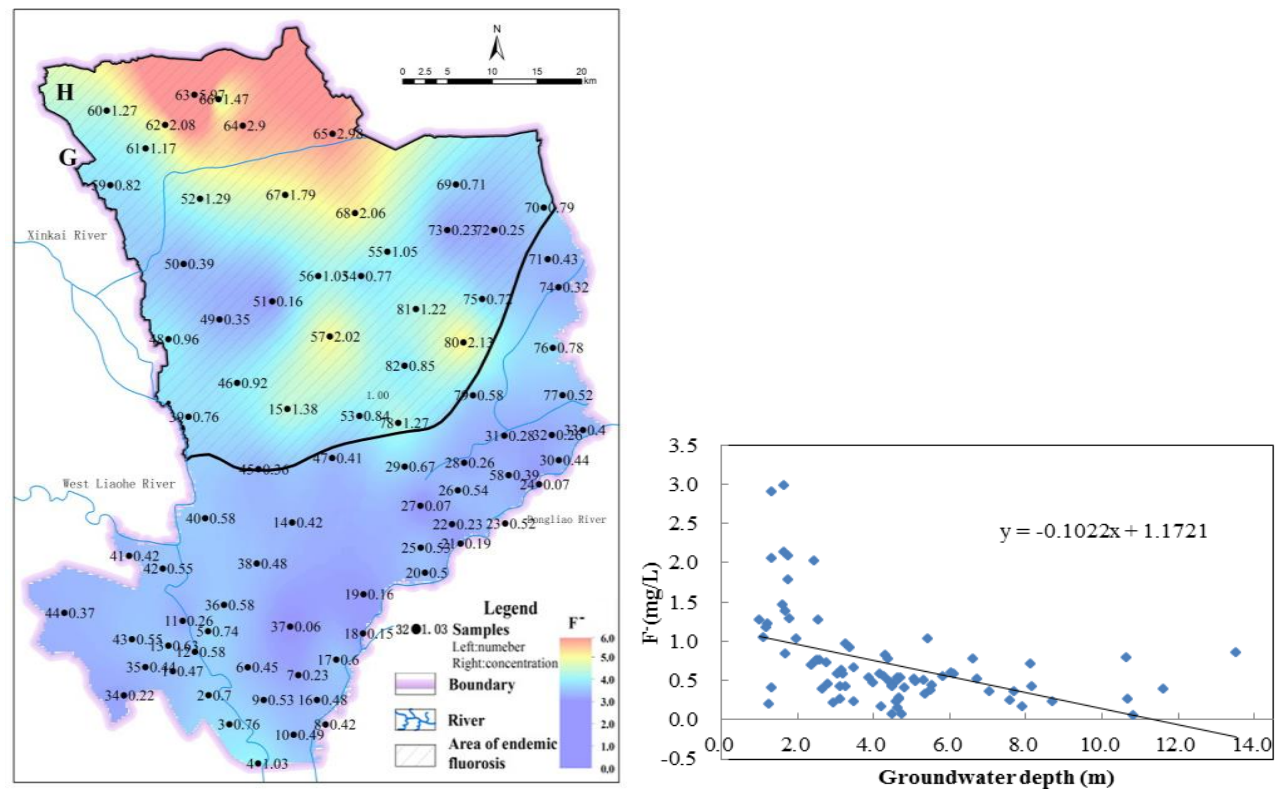

Fig. 1. Contour map of $\mathrm{F}^{-}$concentration.

Fig. 2. Relationship between $\mathrm{F}^{-}$and groundwater depth.

\section{Formation of chemical constituents in groundwater}

The lithology of the Shuangliao aquifer is mostly fine to coarse sand, and sand-gravel, and the aqueduct layer is mostly sandy loess, clay, muddy loam, and mudstone. Fluorine from the aquifer will enter the groundwater directly and become an important direct source of fluorine in this area. Fluorine from the aqueduct layer, will enter each layer of groundwater through leaks or groundwater infiltration. The field investigation showed that soil salinization is at critical levels in areas with high $\mathrm{F}^{-}$concentration in the groundwater. Therefore, it can be deduced that the chemical composition of groundwater in areas of high fluorine is mainly an evaporation-concentration process. Evaporation is one of the main process of the loss of groundwater due to its shallow depth. Evaporation causes the salt content of groundwater to increase near the surface, and through capillary action [4] the salt accumulates in the surface soil, which leads to soil salinization. Since outliers can have a 
significant effect on correlation, the sample with the highest F- concentration was omitted, and a linear regression analysis of groundwater depth and F- concentration was made. The results are shown in Fig. 2. The correlation coefficient was -0.46 . There is a negative correlation between $\mathrm{F}^{-}$concentration and groundwater depth in the study area. According to the field investigation, the groundwater in high fluorine areas is very shallow at around $2 \mathrm{~m}$ (Fig.3b). The degree of soil salinization in this area is affected by the microtopography, either a slight depression or uplift in the Earth's surface will have an important effect on the evaporation intensity of the groundwater. This manifests itself as the low growth rate of grass in low-lying areas and growth of some saline-alkali vegetation on small uplifts (Fig.3c).

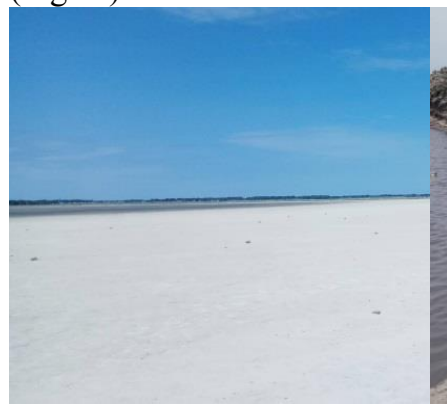

(a)

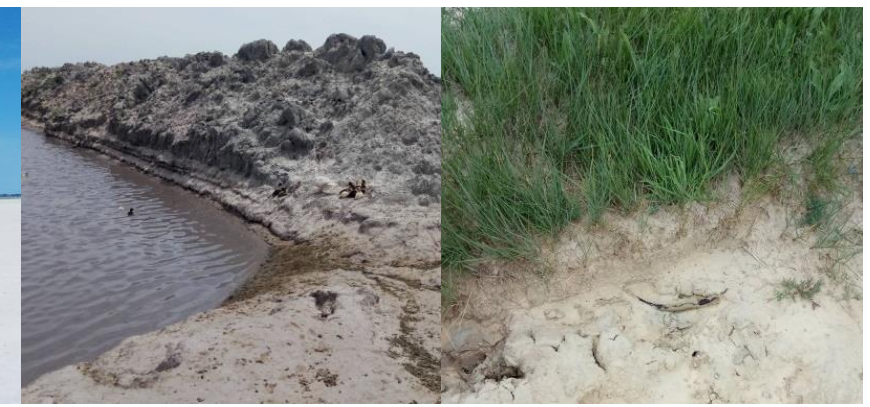

(b) (c)

Fig. 3. Field survey photos of the high fluoride area.

Note: a. saline-alkali soil; b. groundwater depth; c. microtopography.

\section{Hydrogeochemical Characteristics of Fluoride in Groundwater}

\subsection{Relationship of $\mathrm{F}^{-}$and groundwater chemistry}

The Piper diagram (Fig. 4), shows the main types of water chemistry in shallow groundwater: $\mathrm{HCO}_{3}-\mathrm{Ca}, \quad \mathrm{HCO}_{3}-\mathrm{Ca}(\mathrm{Na}), \mathrm{HCO}_{3}(\mathrm{Cl})-\mathrm{Ca}$ and $\mathrm{HCO}_{3}\left(\mathrm{SO}_{4}\right)-\mathrm{Ca}$. The concentration of $\mathrm{F}^{-}$is different for each water type. The highest $\mathrm{F}^{-}$concentration is in the $\mathrm{HCO}_{3}-\mathrm{Ca}(\mathrm{Na})$ type with an average of $0.88 \mathrm{mg} / \mathrm{L}$ and a median of $0.63 \mathrm{mg} / \mathrm{L}$ based on 17 groundwater samples. The lowest $\mathrm{F}^{-}$concentration is in the $\mathrm{HCO}_{3}\left(\mathrm{SO}_{4}\right)-\mathrm{Ca}$ type with an average of $0.27 \mathrm{mg} / \mathrm{L}$ and median of $0.26 \mathrm{mg} / \mathrm{L}$ based on 5 groundwater samples. These results indicate that water type may have a certain effect on the $\mathrm{F}^{-}$content forms.
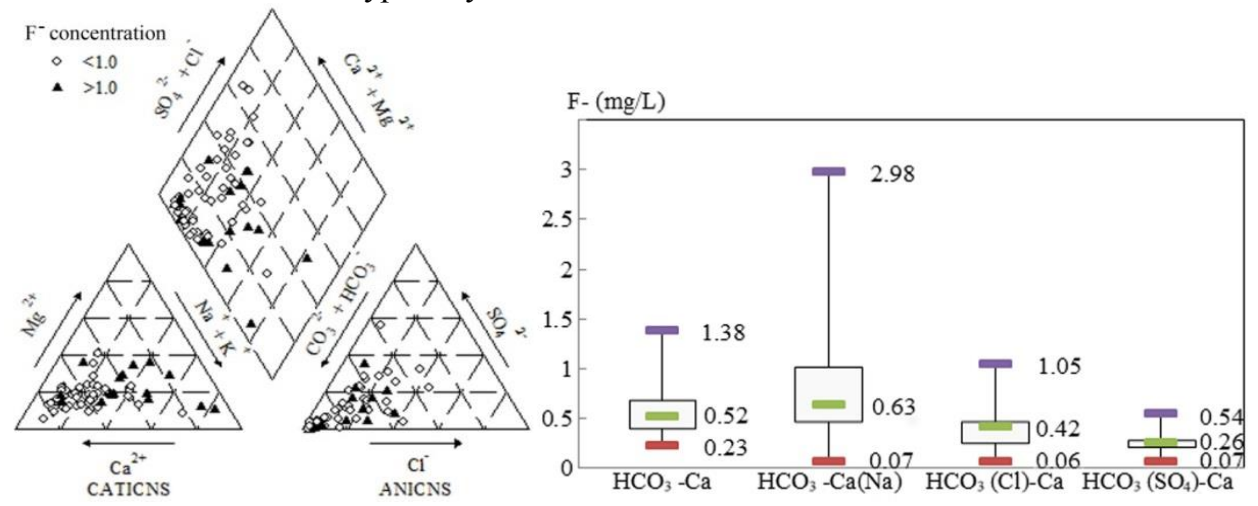

Fig. 4. Piper diagram and box diagram showing $\mathrm{F}^{-}$concentration of groundwater samples. 


\subsection{Relationship of $\mathrm{F}^{-}$and $\mathrm{pH}$}

Groundwater $\mathrm{pH}$ ranges from 7.09 8.38, and groundwater with high $\mathrm{F}^{-}$concentration are mainly in the range of 7.31 7.88. From Fig.5, it can be seen that $\mathrm{F}^{-}$concentration varies with $\mathrm{pH}$ with a positive correlation within a certain range, but the concentration of $\mathrm{F}^{-}$ decreases with increasing $\mathrm{pH}$ above $\mathrm{pH} 7.8$.

\subsection{Relationship of F- and TDS}

The variation range of TDS is $252 \sim 2610 \mathrm{mg} / \mathrm{L}$, and groundwater in the study area is divided into fresh water (TDS $<1000 \mathrm{mg} / \mathrm{L}$ ) accounting for $67 . \%$ of the samples, and brackish water $(1000 \mathrm{mg} / \mathrm{L}<\mathrm{TDS}<3000 \mathrm{mg} / \mathrm{L})$ accounting for $33 \%$. Therefore, the study area is mostly fresh water. It can be seen from Fig. 1 that the variation range of TDS is 513 . $\sim 2240 \mathrm{mg} / \mathrm{L}$ with a $\mathrm{F}^{-}$concentration greater than $1.0 \mathrm{mg} / \mathrm{L}$. However, when TDS is too high, $\mathrm{F}^{-}$concentration tends to decrease. Further analysis shows that the decrease of $\mathrm{F}^{-}$ concentration may be due to the chemical reaction of $\mathrm{F}^{-}$with some ions, which results in the formation of complex compounds and the decrease of $\mathrm{F}^{-}$concentration.

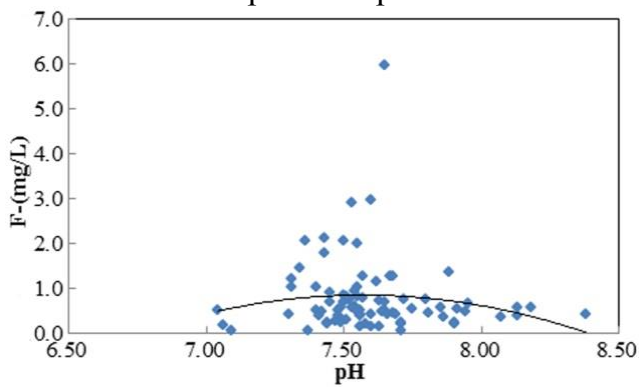

Fig. 5. Relationship between $\mathrm{F}^{-}$and $\mathrm{pH}$.

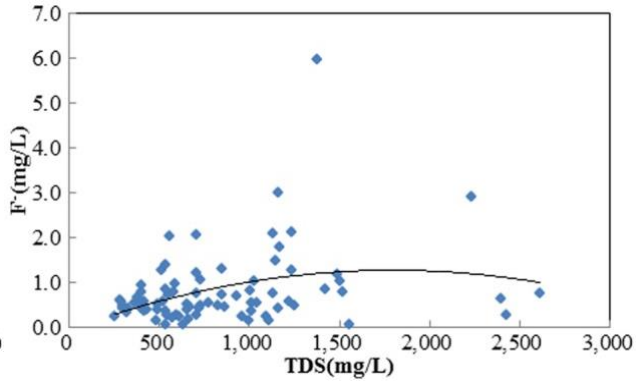

Fig. 6. Relationship between $\mathrm{F}^{-}$and TDS.

\subsection{Relationship of F- and major ions}

Due to its active chemical properties, $\mathrm{F}^{-}$can exchange with different ions in groundwater. Using Pearson correlation analysis, the relationship between $\mathrm{F}^{-}$and the main ions is shown (Table 1). There is a significant correlation between $\mathrm{F}^{-}$and $\mathrm{Na}^{+}(0.53)$, followed by a slightly positive correlation with $\mathrm{HCO}_{3}{ }^{-}(0.39)$, but $\mathrm{F}^{-}$is negatively correlated with $\mathrm{Ca}^{2+}$. The results indicate that $\mathrm{Na}^{+}$and $\mathrm{HCO}_{3}{ }^{-}$promote the enrichment of $\mathrm{F}^{-}$, but $\mathrm{Ca}^{2+}$ restricted the enrichment of $\mathrm{F}^{-}$.

$\mathrm{F}^{-}$reacts with $\mathrm{Ca}^{2+}$ to form $\mathrm{CaF}_{2}$, which precipitates out of solution and reduces the $\mathrm{F}^{-}$ concentration. And that maybe the reason why there is a negative correlation between $\mathrm{Ca}^{2+}$ and $\mathrm{F}^{-}$(Fig. 7). Precipitation and evaporation affect groundwater movement, locally inducing a vertical direction of flow, which increases evaporation and salinization of water and soil. These same processes affect the concentrations of $\mathrm{F}^{-}$and various other chemical components. Since evaporation plays a major role in the enrichment of $\mathrm{F}^{-}$in groundwater and stronger evaporation result in higher TDS (besides the higher the ion concentration of soluble salts, such as $\mathrm{NaCl}$ ), the correlation between $\mathrm{F}^{-}$and $\mathrm{Cl}^{-}$is very important. Figure 8 shows the positive correlation between $\mathrm{F}^{-}$and $\mathrm{Cl}^{-}$. 
Table 1. Pearson correlation coefficient of $\mathrm{F}^{-}$and major ions.

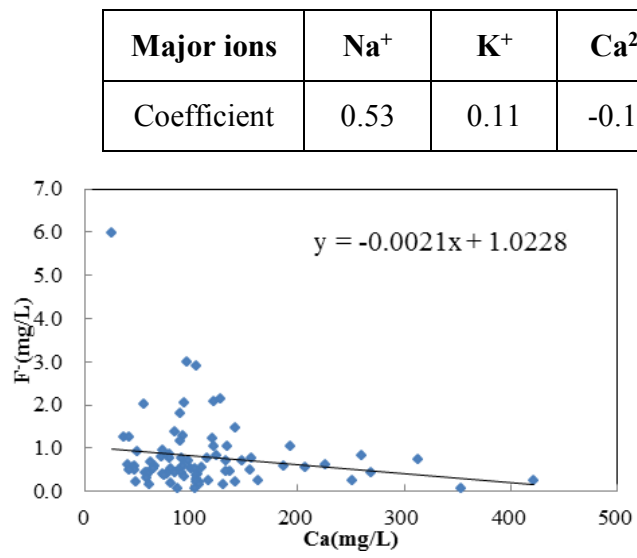

Fig. 7. Relationship between $\mathrm{F}^{-}$and $\mathrm{Ca}^{2+}$.

\begin{tabular}{|c|c|c|c|}
\hline $\mathbf{M g}^{2+}$ & $\mathbf{H C O}_{3}^{-}$ & $\mathbf{C l}^{-}$ & $\mathbf{S O}_{4}{ }^{2-}$ \\
\hline 0.31 & 0.39 & 0.15 & 0.08 \\
\hline
\end{tabular}

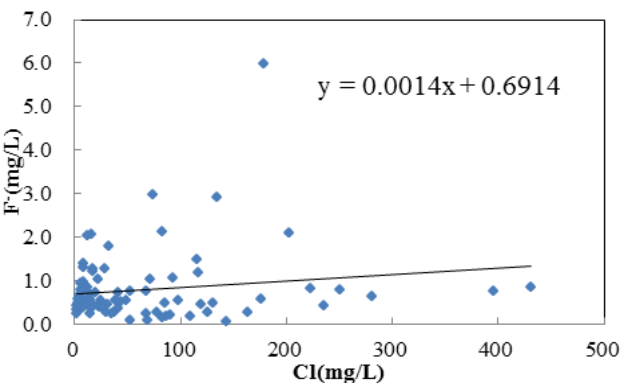

Fig. 8. Relationship between $\mathrm{F}^{-}$and $\mathrm{Cl}^{-}$.

\section{Conclusions}

(1) Fluorine in the groundwater is sourced from the interactions between water and rock, and enriched by evaporation. Evaporative concentration is the main process affecting chemical composition of groundwater in the high $\mathrm{F}^{-}$area, where the groundwater is at a shallow depth and soil salinization is high.

(2) Both $\mathrm{pH}$ (weak alkaline environment) and TDS had a positive effect on $\mathrm{F}^{-}$ enrichment in a certain range, and when the $\mathrm{F}^{-}$concentration exceeds this range it has negative consequences on local health and environment.

(3) $\mathrm{Na}^{+}$and $\mathrm{F}^{-}$have a significant positive correlation; $\mathrm{HCO}_{3}{ }^{-}$and $\mathrm{F}^{-}$had a weak positive correlation, and $\mathrm{Ca}^{2+}$ was the only ion with a negative correlation with $\mathrm{F}^{-}$.

Acknowledgements. This work is supported by the National Natural Science Foundation of China (41572216), the China Geological Survey Shenyang Geological Survey Center "Changji Economic Circle Geological Environment Survey" project (121201007000150012), the Provincial School Coconstruction Project Special - Leading Technology Guide (SXGJQY2017-6), and the Jilin Province Key Geological Foundation Project (2014-13). We thank the anonymous reviewers for their useful comments that helped us improve our manuscript.

\section{References}

1. X.X. Li, P. Wu, Z.W. Han, J.F. Shi. Environ earth sci., 75, 11 (2016)

2. A.K. Haritash, A. Aggarwal, J. Soni, S. Khyati, S. Mohnish, S. Bhupinder. Appl. Wat. Scien., 8, 2 (2018)

3. Y.H. Sun, S.H. Sun, L.J. Lu, G.Q. Chen. Advan. Mater. Res., 581-582 (2012)

4. M.K. Ibrahimi, T. Miyazaki, T. Nishimura, H. Imoto. Arab. Journ. of Geosc., 7, 9 (2014) 